\title{
Influence of acid environment on Collapsibility of Loess
}

\author{
Yao Zhang ${ }^{1}$, Cheng $\mathrm{Jin}^{2}$, Zaiqiang $\mathrm{Hu}^{2}$, Ning $\mathrm{Li}^{2 *}$, Yu Xi ${ }^{1}$ \\ ${ }^{1}$ Shaanxi Key Laboratory of Safety and Durability of Concrete Structures, Xijing University, Xi'an 710123, China. \\ ${ }^{2}$ School of Civil Engineering and Architecture, Xi'an University of Technology, Xi'an 710048, China.
}

\begin{abstract}
Cemented connection of loess is an important internal factor of loess collapsibility, which has a direct impact on its collapsibility. In this study, different concentrations of nitric acid were added to the immersion solution of loess collapsibility test, and the collapsibility sensitivity indexes of loess, such as collapsibility coefficient, stability time and collapsibility rate, were tested under acidic environment and different pressures. At the same time, scanning electron microscope was used to observe the changes of pore and structure of soil samples before and after the test. The test results show that in acid solution, the collapsibility coefficient of collapsible loess increases more under low pressure, and the collapsibility stability time of collapsible loess increases under different pressures. Loess has different collapsibility sensitive pressure range in aqueous solution and acidic solution. The structural strength of collapsible loess has an important influence on the depth of collapsible loess.
\end{abstract}

\section{Introduction}

As a quaternary sediment, loess is widely distributed in the world, accounting for about one tenth of the land area. China is the country with the widest and deepest loess distribution in the world, mainly distributed in the Loess Plateau in Northwest China, North China Plain and the south of Northeast China, covering an area of 631000 square kilometers, accounting for about $6 \%$ of the land area of the whole country[1][2]. Loess has a unique property - collapsibility, which is different from other sediments in the same period, that is, loess collapses rapidly after being soaked by water under self weight or external load[3]. This characteristic of collapsible loess often brings serious damage to the geotechnical engineering built on this kind of loess [4] [5].

Because salt crystal cementation belongs to microstructure, it is difficult to test its mechanical properties by conventional mechanical tests. Therefore, there are few experimental studies on the effect of salt crystal cementation on loess collapsibility and collapsibility sensitivity at home and abroad. In order to understand the mechanism of salt crystal cementation in loess collapsibility and collapsibility sensitivity, this paper uses the characteristic that nitric acid can rapidly dissolve salt crystal cementation, adds different concentrations of nitric acid into the immersion solution of loess collapsibility test, and tests the collapsibility sensitivity indexes of loess, such as collapsibility coefficient under different acidic environments and different pressures.

\section{Test method}

In order to achieve the above research purposes, in the acid collapsibility test and conventional collapsibility samples, the collapsibility stability time, collapsibility coefficient, collapsibility rate and other important collapsibility sensitivity indexes of loess are mainly investigated and analyzed. In order to further analyze the test phenomenon and prove the conclusion, the scanning observation of the microstructure of typical soil samples before and after the test was carried out by using the electronic microscope equipment

(1) The basic physical indexes of soil samples and the content of calcium carbonate are determined according to the relevant provisions of SL237-1999, so as to ensure that the calcium carbonate of soil samples can be fully dissolved in $2 \mathrm{~mol} / \mathrm{L}$ nitric acid solution.

(2) Preparation of solutions with different concentrations: Calculate the amount and mass of nitric acid needed for a certain volume of $0.3 \mathrm{~mol} / 1$ and $2 \mathrm{~mol} /$ $\mathrm{L}$ nitric acid solution, weigh it in a conical flask or other containers and configure it.

(3) Collapsibility test of different concentrations of solution

1) Twenty one $50 \mathrm{~cm} 2$ ring knife samples were divided into three groups. Each group of 7 samples were pressurized to $25,50,100,200,400,800$ and $1600 \mathrm{kpa}$ respectively until the deformation was stable (the settlement per hour was not more than $0.01 \mathrm{~mm}$ ).

2) After the above samples are pressurized and stabilized, distilled water, $0.3 \mathrm{~mol} / 1$ and $2 \mathrm{~mol} / \mathrm{L}$ nitric acid solutions are injected into the water injection tank of the consolidometer respectively, and the values are 
recorded every half an hour according to $0.10(6 \mathrm{~S}), 0.25$ $(15 \mathrm{~s}), 0.5$ (30s), 1.00, 2.25, 4.00, 6.25, 9.00, 12.25, 16.00, $20.25,25.00,30.25,36.00,42.25,49.00$ and $64.00 \mathrm{~min}$, Until the deformation is stable (the subsidence per hour is not more than $0.01 \mathrm{~mm}$ ).

(4) The microstructure of undisturbed soil sample and soil sample after collapsing with distilled water, $0.3 \mathrm{~mol} / 1$ and $2 \mathrm{~mol} / \mathrm{L}$ nitric acid solution under 50, 200 and $800 \mathrm{kpa}$ load were observed by electron microscope.

\section{Test results and analysis}

\section{1 comparison of collapsible deformation}

Fig. 1 is a graph of collapsible deformation varying with time. It can be seen from Fig. 1 (a) that the collapsible deformation of the sample immersed in distilled water increases from $25 \mathrm{kpa}$ to $400 \mathrm{kPa}$, and decreases at $400 \mathrm{kPa}$ and $1600 \mathrm{kpa}$. In the range of $25 \mathrm{kpa}$ to $400 \mathrm{kPa}$, the collapsible deformation increases with the increase of pressure, because under low pressure, the strength of cemented connection before immersion can support the upper load. However, after immersion, the cementation formed by salt gradually dissolves in the water. The matric suction also decreases rapidly, which leads to the decrease of skeleton strength and the difficulty of bearing the upper load, resulting in the rapid failure of the structure.

The results show that the soil particles slide to the hole, the space between particles decreases, and the soil sample is compressed. With the increase of pressure, the connection between soil particles is easier to be destroyed and the soil sample is easier to be compressed. At $400-1600 \mathrm{kpa}$, the main reason for the reduction of collapsible deformation is that the structure of soil sample has been seriously damaged by higher additional pressure before immersion. Even the harder joints in soil (including cemented joints formed by insoluble salts such as calcium carbonate) are still difficult to resist this degree of load, and finally the soil sample has been fully compressed, However, the collapsible space becomes smaller in the later stage. This inference can be fully proved from the physical parameters of the soil sample after compression stability at all levels of pressure in Table 2. When the pressure in Table 2 increases from 25 to $200 \mathrm{KPa}$, the dry density of the soil sample changes from 1.32 to 1.34 , the void ratio changes from 1.06 to 1.02 , and the compression coefficient changes from 0.011 to 0.028 , but the change is not obvious at $400 \mathrm{kPa}$, reaching $1.40,0.94$ and 0.0698 and $1600 \mathrm{kpa}$ respectively.

The variation is obvious and all parameters reach the peak value. It can be concluded that the structure of the soil sample can be destroyed and the soil sample can be fully compacted when the strength of the cemented connection of the soil sample is higher than that caused by the pressure increase. Therefore, the strength of the cemented connection must be an important factor affecting the occurrence of collapsibility. Because of the low strength of the cemented connection, the upper part only needs a small load to collapse, otherwise it is difficult to collapse.

It can be seen from Fig. 1 (b) and (c) that when immersed in $2 \mathrm{~mol} / \mathrm{L}$ and $0.3 \mathrm{~mol} / 1$ nitric acid, the collapsible deformation increases from $25 \mathrm{kpa}$ to $200 \mathrm{KPa}$ in turn, $200 \mathrm{KPa}$ is the peak of collapsible deformation, and decreases from $200 \mathrm{KPa}$ to $1600 \mathrm{kpa}$ in turn. The reason for the earlier peak value of collapse deformation is shown in 3.2 comparison of collapse coefficient.

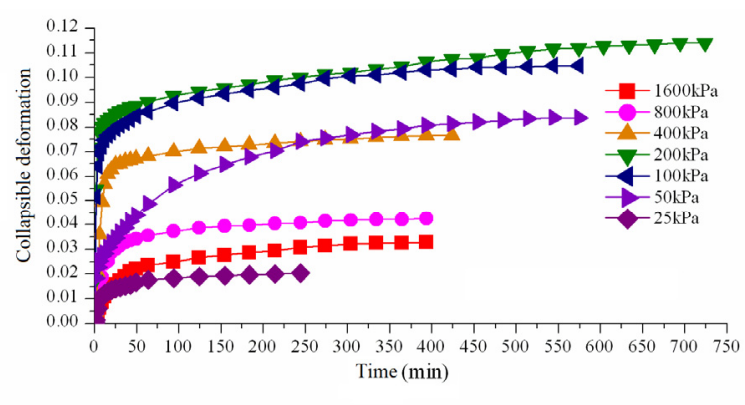

(b) $0.3 \mathrm{~mol} / \mathrm{L} \mathrm{HNO}_{3}$

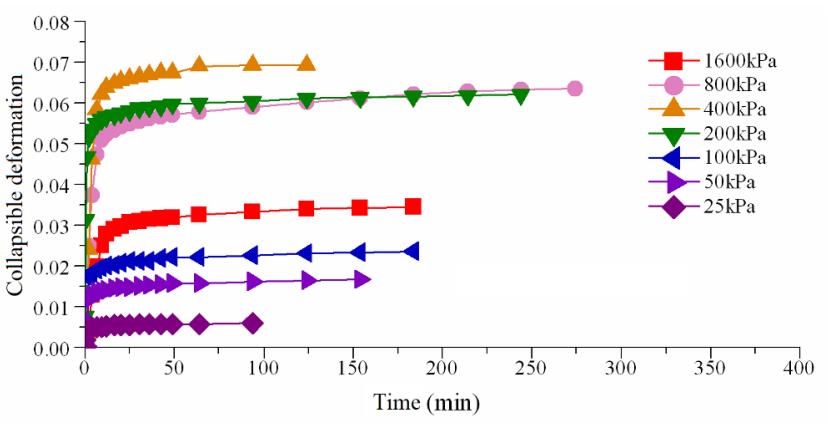

(a) Distilled water

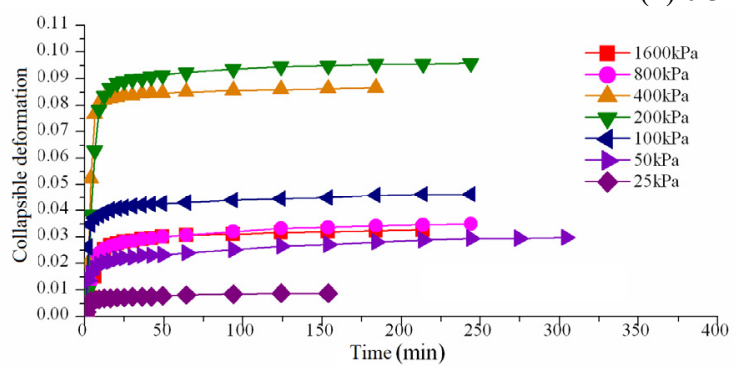

(c) $2 \mathrm{~mol} / \mathrm{L} \mathrm{HNO}_{3}$

Figure 1. Relationship between collapsible deformation and time at different vertical pressures 


\section{2 comparison of collapsibility coefficient}

It is not difficult to see from Figure 2 that the collapsibility coefficient and pressure of the three solutions show a curve relationship of first increasing and then decreasing, which is consistent with the results of other loess collapsibility tests [2] [5] [6] [7]. See the analysis in the previous section for the reasons. Comparing the three curves, it can be seen that the initial pressure of collapsibility decreases from $44 \mathrm{kPa}$ of aqueous solution to $33 \mathrm{kPa}$ and $19 \mathrm{kPa}$ of acid solution respectively, and the peak value of collapsibility decreases from $400 \mathrm{kPa}$ of aqueous solution to $200 \mathrm{kPa}$ of acid solution. Under the load of $25-200 \mathrm{kpa}$, the collapsibility coefficient of nitric acid immersed in $2 \mathrm{~mol}$ / $\mathrm{L}$ is much larger than that immersed in distilled water. Under the same condition, the collapsibility coefficient of nitric acid immersed in $0.3 \mathrm{~mol} / 1$ is between $2 \mathrm{~mol} / \mathrm{L}$ and distilled water. $0.3 \mathrm{~mol} / 1$ nitric acid is slightly larger at $400 \mathrm{kPa}$, distilled water is larger than acid solution at $800 \mathrm{kpa}$, and the three are almost equal at $1600 \mathrm{kpa}$. Generally speaking, there is no obvious difference in acid solution at $800-1600 \mathrm{kpa}$.
This paper analyzes and considers that: at a lower pressure, adding an appropriate amount of nitric acid at $25-400 \mathrm{kpa}$ can dissolve the calcium carbonate cementation which is not destroyed by the relationship between collapsibility coefficient and pressure in different solutions in Fig. 2, so as to promote the collapsibility of loess. Nitric acid solution acts as a similar catalyst, but at 400-1600kpa, The calcium carbonate in loess has been destroyed under the high pressure before immersion, and the soil sample has been fully compressed (especially at $800 \mathrm{kpa}$, the compression deformation of the sample with pre immersion water has been 0.245 , which is much higher than that of the sample with pre immersion $2 \mathrm{~mol} / \mathrm{L}$ and $0.3 \mathrm{~mol} / 1 \mathrm{acid}$, which is 0.2 and 0.225 , which makes the later collapsible deformation smaller). However, the moisture content did not change at this time, and the matric suction still existed. After immersion, the rapid disappearance of matric suction became the main factor of collapsibility . Therefore, the "catalytic" advantage of nitric acid in the rapid dissolution of calcium carbonate can not be revealed under high pressure.

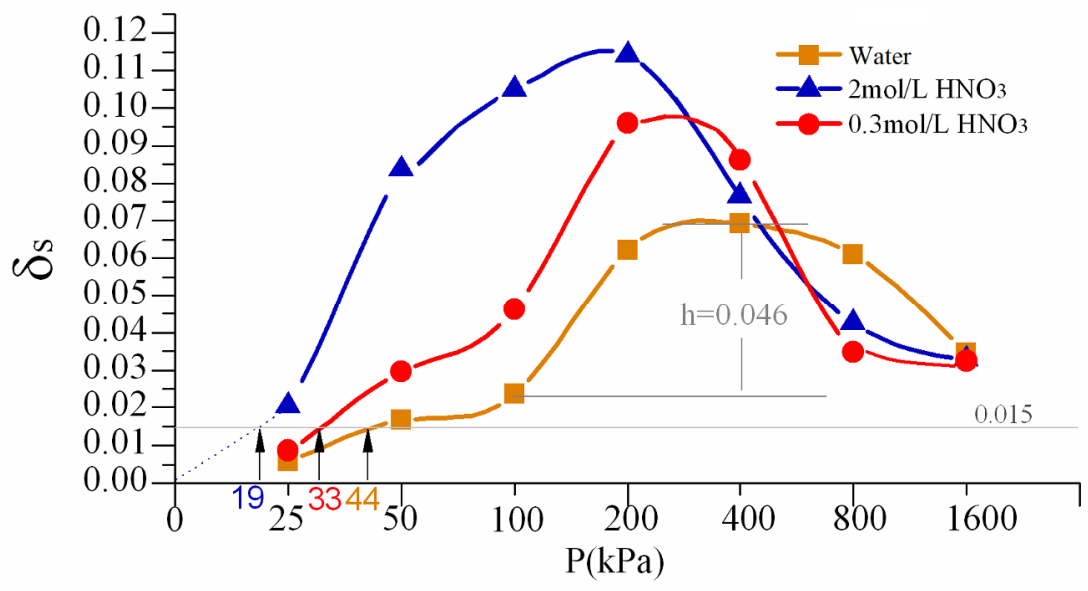

Figure 2. Comparison of coefficient of collapsibility in different solutions at different vertical pressures

This phenomenon can be confirmed by the scanning electron microscope of some soil samples in Fig. 3. In Fig. 3, at $50 \mathrm{kPa}$, the macropores of soil samples immersed in aqueous solution are larger and more than those immersed in $0.3 \mathrm{~mol} / 1$ and $2 \mathrm{~mol} / \mathrm{L} \mathrm{HNO}_{3}$; When the pressure is $200 \mathrm{kPa}$, the macropores of the soil immersed in aqueous solution are reduced, and the macropores of the soil immersed in $0.3 \mathrm{~mol} / \mathrm{L}$ and $2 \mathrm{~mol}$ / $\mathrm{L} \mathrm{HNO}_{3}$ are eliminated; When the pressure is $800 \mathrm{kPa}$, the macropores of the three solutions are eliminated. This phenomenon also proves that there is a certain strength in the cementation of insoluble salts such as calcium carbonate, which can be destroyed by higher load, which is similar to the viewpoint that pressure can destroy the macropore structure of loess proposed by vilar1 and Rodrigues. Therefore, there should be a certain relationship between the buried depth of collapsible loess and the strength of calcium carbonate cementation. The stronger the calcium carbonate cementation is, the deeper the collapsible loess is.

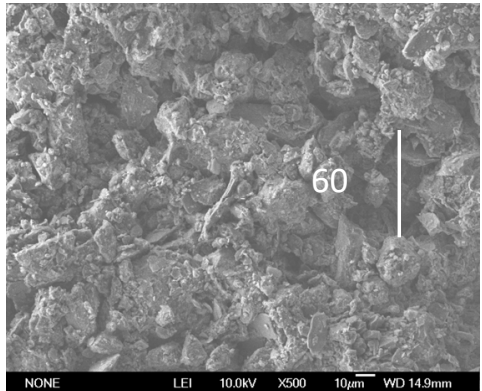

(a) $50 \mathrm{kPa}$, distilled water solution

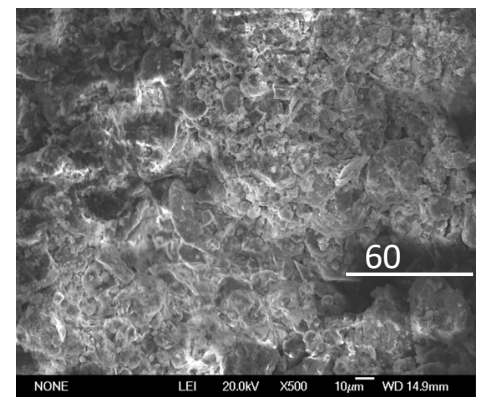

(b) $50 \mathrm{kPa}, 0.3 \mathrm{~mol} / \mathrm{L} \mathrm{HNO}_{3}$

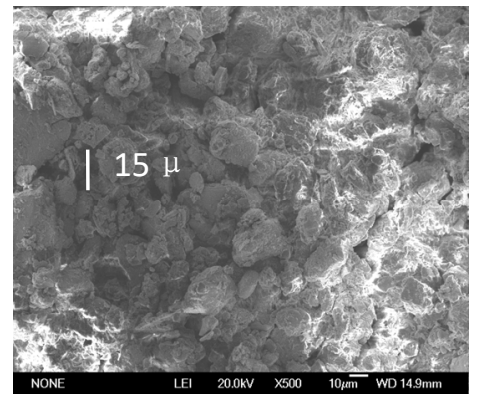

(c) $50 \mathrm{kPa}, 2 \mathrm{~mol} / \mathrm{L} \mathrm{HNO}_{3}$ 


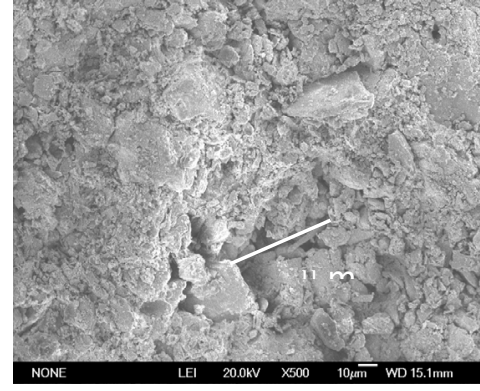

(d) $200 \mathrm{kPa}$, distilled water solution

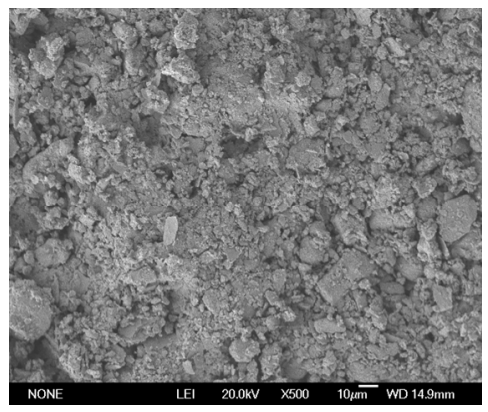

(g) $800 \mathrm{kPa}$, distilled water solution

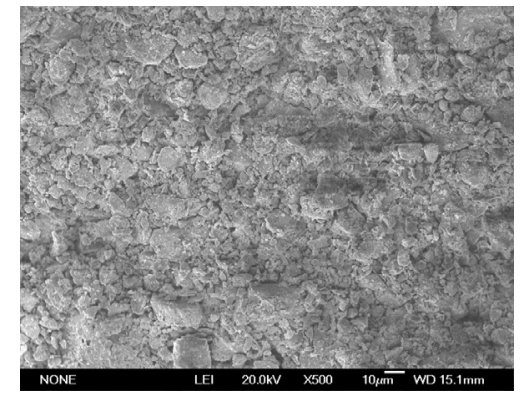

(e) $200 \mathrm{kPa}, 0.3 \mathrm{~mol} / \mathrm{L} \mathrm{HNO}_{3}$

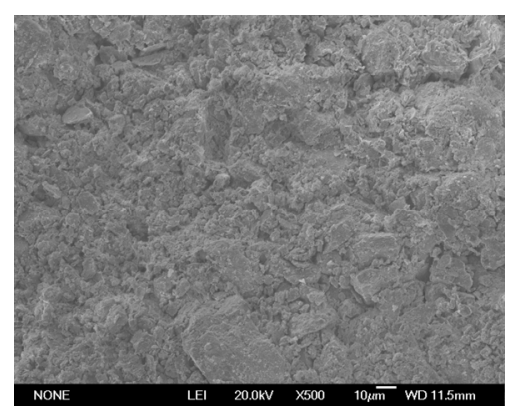

(h) $800 \mathrm{kPa}, 0.3 \mathrm{~mol} / \mathrm{L} \mathrm{HNO}_{3}$

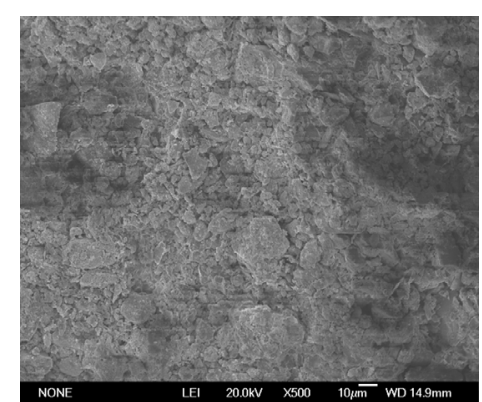

(f) $200 \mathrm{kPa}, 2 \mathrm{~mol} / \mathrm{L} \mathrm{HNO}_{3}$

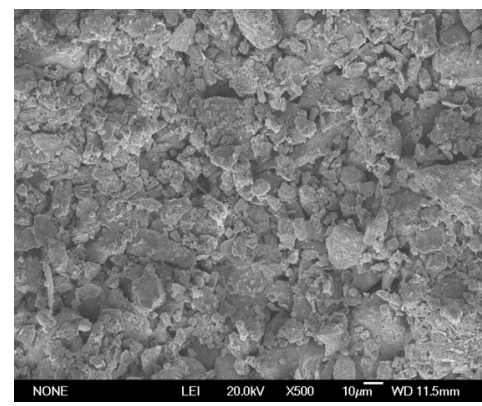

(i) $800 \mathrm{kPa}, 2 \mathrm{~mol} / \mathrm{L} \mathrm{HNO}_{3}$

Figure 3. 500 times SEM figures of samples in different solutions at different vertical pressures

\section{Conclusion}

(1) Through the study of collapsibility deformation and collapsibility coefficient, it is found that the collapsibility of collapsible loess in acid solution and distilled water solution can be divided into two cases. One is in the case of low pressure (below $400 \mathrm{kPa}$ in this paper), the collapsibility coefficient of collapsible loess in acid solution is much larger than that in water solution, and the initial pressure and peak value of collapsibility decrease at the same time. The main reason is that the acid solution helps to dissolve the insoluble salt crystal cementation in Loess and promotes the occurrence of collapsibility.

(2) The other is that under high pressure (above $400 \mathrm{kPa}$ in this paper), the collapsibility coefficient of collapsible loess in acid solution is not significantly different from that in water solution. The main reason is that the macropores and overhead voids formed by cementation connection in collapsible loess have been fully destroyed and compacted under high load before immersion, which makes the later collapsible space small.

\section{Acknowledgements}

This work was supported by the China Postdoctoral Science Foundation (Grant No. 2020M673617XB), the Open Research Fund of State Key Laboratory of Geomechanics and Geotechnical Engineering, Institute of Rock and Soil Mechanics, Chinese Academy of Sciences (Grant No. Z020019), the special Foundation for High Level Talents of Xijing university (Grant No. XJ20B12).

\section{Reference}

1. Gao, G. R. The distribution and geotechnical roperties of loess soils, lateritic soils and clayey soils in China [J] Engineering Geology, 1996, 42 (1): 95-104.

2. Nouaouria, M. S., Guenfoud, M., Lafifi, B. Engineering properties of loess in Aleeria [J]. Engineering Geology. 2008, 99(1): 85-90.

3. Zhu Yuan-qing, Chen Zheng-han. A new method of studying collapsibility of loess [J]. Chinese Journal of Geotechnical Engineering 2008, 30 (4): 524-528.

4. Buscarnera, G., Prisco, C.Di. Soil stability and flow slides in unsaturated shallow slopes: can saturation events trigger liquefaction processes? [J]. Geotechnique 2013, 63 (10): 801-817.

5. Mihalache, C., Buscarnera, G. Is wetting collapse an unstable compaction process? [J]. Journal of Geotechnical \& Geoenvironmental Engineering. 2015, 141 (2).

6. Wang Guo-lie. The collapsibility and collapse sensitivity of loess [J]. Quaternary Sciences, 1986(01): 57-60 (in chinese))

7. Zhang Yuan-ding. Discussion on the sensitivity of loess collapse $[\mathrm{J}]$. Chinese Journal of Geotechnical Engineering, 1996, 18 (5): 136-140. 